\title{
Inclusive Approach to the Psycho-Pedagogical Assistance of Distance Learning
}

\author{
Daniya Z. Akhmetova ${ }^{1}$ \\ ${ }^{1}$ Institute of Economics, Management and Law, Kazan, Russia \\ Correspondence: Daniya Z. Akhmetova, Institute of Economics, Management and Law, 42 Moskovskaya str., \\ 420111 Kazan, Russia. Tel: 7-843-231-9291. E-mail: ahmetova@ieml.ru
}

Received: August 9, 2014 Accepted: September 11, 2014 Online Published: October 29, 2014

doi:10.5539/ies.v7n11p136 URL: http://dx.doi.org/10.5539/ies.v7n11p136

\begin{abstract}
Author focuses on three groups of problems: quality of distance learning and e-learning; necessity to develop the facilitation skills for teachers who work using distance learning technologies; realization of inclusive approach for the organization of distance learning in inclusive groups where people with disabilities study with people without any disabilities. The conclusions and main ideas of author are based on the theoretical researches and her perennial experience as a head of big department which trains student by distant form and which realizes creative projects also at Russian and international level.
\end{abstract}

Keywords: distance learning, facilitation, teacher-facilitator, inclusive education, psycho-pedagogical assistance, inclusive approach

\section{Introduction}

One of the modern trends in education is inclusive approach to the organization of educational process in educational institutions. Inclusive education provides equal opportunities for the people who have special educational needs and possibilities. The main mission of inclusive education is not only teaching and educating people with disabilities, but also training social skills such as communicative, adaptive, moving, labor and others. The strength of character, the ability to overcome the life difficulties, support of your own hygienic state, achievement of harmony and happiness play important role in the life of people with disabilities. Therefore the problem of organizing the educational process for students with disabilities becomes more relevant.

\section{Background}

There is an opinion that the most comfortable form of study for people with disabilities is distant form. Distance learning is acceptable for those people who cannot attend educational institutions. Nevertheless distance learning is not the form of inclusive education. It doesn't allow organizing the live communication between people with disabilities and those without any restrictions in health and therefore it leads to the loss of educational effect of the process of joint education.

Wide use of info-communicative technologies in education has some problems which should be overcome due to the special approach which allows minimizing the psychological and physiological restrictions. The research of psycho-pedagogical aspects of implementing information technologies in the educational system has revealed the advantages and disadvantages of using distance learning technologies in education (Table 1). 
Table 1. Advantages and disadvantage if using distance learning technologies

\begin{tabular}{ll}
\hline Advantages & Disadvantages \\
\hline $\begin{array}{l}\text { 1. Using computers in order to intensify the educational } \\
\text { process. }\end{array}$ & $\begin{array}{l}\text { 1. Health impairments (vision, cardiovascular disease, } \\
\text { scoliosis, etc.). }\end{array}$ \\
$\begin{array}{l}\text { 2. Addressing the employment challenge of children and } \\
\text { young people (computer games, the Internet). }\end{array}$ & $\begin{array}{l}\text { 2. Internet-addiction which leads to the physical and } \\
\text { mental disorders. }\end{array}$ \\
$\begin{array}{l}\text { 3. The opportunity to communicate with the peers and } \\
\text { people from all over the world (social networks such as }\end{array}$ & $\begin{array}{l}\text { 3. Probability to be in a dysfunctional Internet } \\
\text { environment (harmful blogs, websites, etc.). }\end{array}$ \\
$\begin{array}{l}\text { Facebook, My world and many others). } \\
\text { 4. Unlimited communications through the Internet. }\end{array}$ & $\begin{array}{l}\text { 4. Problems of social infantilism in "native" society; } \\
\text { problems of adaptation to life; social immaturity. }\end{array}$ \\
$\begin{array}{l}\text { 5. More democratic and «pure» forms and technologies of } \\
\text { learning and knowledge control (testing, Internet-learning, } \\
\text { etc.). }\end{array}$ & $\begin{array}{l}\text { 5. Unilateral control and limited opportunities to identify } \\
\text { personal qualities and knowledge in the educational } \\
\text { 6. Opportunity of wide implementing of the distance } \\
\text { learning technologies in the educational process. }\end{array}$ \\
$\begin{array}{l}\text { 7. Distance learning is developed under the term «distance } \\
\text { educational technologies». }\end{array}$ & $\begin{array}{l}\text { 7. Distance learning is the form of education along with } \\
\text { full-time, part-time of education in such countries as }\end{array}$ \\
& $\begin{array}{l}\text { Kazakhstan, Kyrgyzstan, Belarus, while in Russia } \\
\text { distance learning includes using distance learning } \\
\text { technologies. }\end{array}$ \\
\hline
\end{tabular}

Distance learning is a system and process of learning where the teacher and the students are geographically separated and therefore rely on the electronic and printed manuals for the organization of the educational process; distance learning includes remote teaching (activity of the teacher in the learning process) and learning (cognitive activity of students) processes. Training in using distance learning technologies can provide the quality of students' knowledge due to the presence of psycho-pedagogical support of this system and development of each individual component of the system.

Each educational institution has its own distance learning system, its own educational environment that provides a certain level of quality of education. The organizers of the distance learning while modeling the system must provide possible approaches and techniques of diagnostics and psycho-pedagogical support of the learning process in order to ensure its quality.

Distance learning is realized using information technologies. In some cases information technologies are understood as certain research area, in others - a particular way of working with the information, as well as complex of knowledge about the ways of working with information resources; the method and means of data collection, processing and transmission of information to obtain new information on the object of study. Thus, we understand information technology as a pedagogical technology, which is characterized by a variety of means of communication and provision of information to the user (customer services) with the help of software and hardware (movies, audio, video, computers, and telecommunications networks). It is also important to highlight the availability of communication through interactive programs, which are widely used in training with the use of multimedia, virtual reality systems. They allow to use the text, graphics, video and animation in the dialogue, and thereby to expand the scope of the computer in the learning process. In such systems the illusion of "user's location" among other members of the virtual world is created.

Increased popularity of distance learning is associated primarily with the development of modern information technology that can provide "presence effect" in the classroom of learner. These technologies are implemented into all spheres of human activities, as it is obvious that you need to learn permanently in order to keep pace with the rapidly changing world, and distance learning form of education - one of the acceptable forms of education that allows you to "catch up with the fleeing time".

In order to determine the students' opinion regarding online education we have carried a survey among 2700 students, which included 5 questions. Online students were asked the following questions: 
- Why did you choose an online course?

- What are the advantages of online learning?

- What new competences do you acquire?

- What social skills do you acquire?

- How often do you use Skype or OpenMeetings?

Summary of results

The main reasons for students choosing online education were employment and family responsibilities (maternity leave, small kids, and large families). Most of the university's online students live in remote regions of Russia or in neighboring countries. Therefore this form of study is very convenient for the students who live far from the institute.

- More than $70 \%$ of the students in the study stated that their main motivation for studying online was "The possibility to study at any convenient time." Moreover, most students considered that their computer skills/digital literacy had improved due to distance learning.

- "Does distance learning help you widen your opportunities in life and career?" $83 \%$ of students replied positively. In Russia, as abroad, social networks are used in the learning process.

- $\quad 97 \%$ of online students use learning communities in social networks. $62.5 \%$ of students use My world (Мой Мир http://corp.mail.ru/), 12.5\% use Twitter and the remaining 25\% use Facebook and Odnoklassniki.ru.

- A separate study was carried out at the Institute among Malagasy students who study Russian language on-line. These students had poor computer skills at the start of the online course but at the end of the course the students remarked that distance learning had enabled them to raise their level of computer literacy and digital skills as well as being able to apply the knowledge they gained in everyday situations. $90 \%$ of the Malagasy students used forums, chat and e-meeting tools like OpenMeetings and Skype during the learning process.

The century-old teaching experience shows that good education can be obtained only due to the presence of teaching materials and textbooks, due to educational interaction between teacher and student. Such contact in distance learning is quite limited; therefore this interaction should be implemented into the information technologies which are used in distance learning. In contradistinction to the printed textbooks it is easy to realize the elements of such dialogue through computer technologies.

Distance learning also involves self-education. However we exclude the possibility just of independent studying of educational programs. Nowadays in Russia there are insufficient means of transmitting information, the culture of information exchange is not high. Most students for example with the first higher education and work experience possess the skills of self-teaching. High school alumni do not have sufficient experience in organizing their own learning activities. While creating a distance learning system this circumstance should be taken into account.

While choosing the future profession which is provided by various methods of distance learning a person first follows to his/her natural inclinations, identity. This means that professional orientation is the leading component of individualization of learning, it gives the real opportunities for the effective use of intellectual potential, for the targeted development of abilities through the system of individual tasks for students. The main positive point is that the distance learning technologies develop the student's responsibility and cause the need not only to acquire knowledge independently, but also to apply them to solve specific professionally significant situations in life.

Nowadays there are many researches on the organizational, technical, contextual aspects of e-learning. Polat et al. (2004) outlines several approaches to the organization of the educational process with the use of e-learning which has huge resources (technical and informational). She convincingly argues that computer telecommunications, information resources and Internet services allow realizing a fundamentally new approach to training and educating of students. Such approach is based on a broad communication, rapprochement, erasing the boundaries between individualities; on the free exchange of opinions, ideas, on the natural desire to learn new things and expand their horizons. It is based on real research methods of scientific or creative teacher's laboratory, it allows studying the laws of nature, the basics of technology, social phenomena in their dynamics during the process of solving vital problems, and also features of various types of creation in the joint activities of the groups of participants. This approach is also based on extensive contacts with other cultures, with other 
people's experiences (Polat et al., 2004). The emotional presence in online environment as a fundamental element in an online community is studied by Cleveland-Innes and Campbell (2012). The influence of culture on students' learning and engagement in asynchronous learning networks is studied by Uzuner (2009). Many scientists in their researches study the problem of group facilitation, student support (Jung \& Hong, 2014), pedagogical roles and competencies of university teachers practicing in the e-learning environment (Carril, Sanmamed, \& Selles, 2013). The Pedagogy of mobile learning in supporting distance learners, the problem of interaction in distance education was investigated in research of Makoe (2012), Daniel and Marquis (1979), and Bernard et al. (2009).

After reviewing the researches we can conclude that there is a need to deeper study the problem of psycho-pedagogical development of distance learning system. Distance learning is often presented as algorithmic system, which is strictly regulated. But the person factor is out of sight in many researches. In this regard, it is necessary to consider three groups of participants and subjects of educational process organized with distance learning technologies whose psychological state influence the quality of education.

First group of people - assistance team (managers, IT-specialists who coordinate the educational process). The main task of this group of people is the selection of staff to accompany the educational process. This group of employees must be constantly in sight of the head of educational institution. They should be taught to reflect, to understand the complexity of the problems and to help students in their decisions, to provide the services.

In opinion of Brushlinsky, reflection is a peculiar way of an active attitude to his/her own life, which begins to develop at the early stages of ontogenesis (Brushlinsky, 2003). In the process of education social and psychological skills of the students such as transformative activity, integrity, autonomy, freedom of action, harmony, focus and awareness are developed. Reflective subject can be considered as a facilitator. Facilitation is the result of moral and behavioral manifestations of reflective subject.

\section{Facilitation in Distance Learning}

Facilitation involves mentalizing organization of group and individual work aimed at identifying the difficulties in learning activities and at teaching subjects to assist them in achieving the result. Implementation of facilitation approach improves the efficiency of group work, allows engaging all subjects in activities, revealing the potential of teaching subjects.

Teacher is the main figure in the educational process, but many high school teachers begin to work without adequate psychological and pedagogical training. They possess the knowledge in their specialized area, but poorly represent problems of students. Many teachers believe that the students must regularly develop their own study themselves, they must look for teachers to solve the difficulties that arise, but the teachers do not overlook the fact that not all students are motivated to study for some reasons (life problems, restrictions in health, etc.). A survey of students' satisfaction by the process of teaching and tutor support of their learning activities shows the following unresolved problems: "teacher does not often respond to questions from the students", "tasks sometimes are too difficult and uninteresting", "teacher is indifferent to student success", etc. One of the reasons of indifferent attitude of the students to study is the lack of teachers' knowledge and use of technology facilitation. It is connected, primarily, with the poor training of teachers in the field of pedagogy and psychology. Teachers cannot and do not want to be around and together with the students when they have difficulties such as lack of skills, of knowledge, depression associated with various life circumstances, apathy, changing social values and priorities and others. Observations of the work show that only a few of them have the ability to guess the sensitive and momentary state of students. Most of the teachers have the following position-"student must find the decision of difficult situation himself/himself". The students become unmotivated and they drop out of the course.

In order to develop facilitation skills we have created a system of raising teachers' facilitation skills. In the beginning of every year we organize courses with the objective of raising teachers' ICT skills and their psychological-pedagogical competence. These courses include issues of providing facilitation and motivation of students. This starts with a theoretical orientation and includes the following themes: "Humane pedagogy as the theoretical basis of facilitation", "Tolerance in the educational process", "Technology of facilitation", "Study and reflection", "What does it mean to be a sensitive person?".

The main point of these lessons is that they are carried out in training way and they are finished by visualization, which allows to "pass through yourself - through consciousness and heart". The lessons create empathy and eidetism, actualizing the skills of putting yourself in the student's place that positively influence the psychological assistance in the educational process. Such common training of teachers to prepare them for their online teaching using Skype and Open Meetings systems. Using these systems allows a maximum level of 
contact in an online environment. In addition to the skills mentioned above the teachers should possess certain elements of acting, because the e-meeting environment puts focus on expressive elements such as the teacher's facial expressions, gesture, tone of voice and look and these factors should suit the plan of the lesson and assist facilitation. Our practice shows that students and teachers feel psychological barriers when they communicate on-line at first. Maybe the reason is imperfect speech: tongue-tied, inexpressiveness, poverty of speech, definite stylistic errors. There are some cases when students and teachers are lost, are ashamed to say, are critical about their image when they look at themselves on a monitor or a screen. That causes a reluctance to appear on screen and use such interactive tools. This reluctance can be overcome by pre-training in using on-line tools. Video-training takes place before the beginning of on-line lessons using Skype and OpenMeetings. Students and teachers are offered short texts of performance, which consist of expressive phrases and sentences. After pronunciation of these texts first by reading on paper, then by rote in the most expressive way, self-analysis and self-assessment takes place. Frequently the teachers are dissatisfied with their facial expression and tone of voice in the recorded sessions. At this point they receive training from a public speaking expert who will work with the speaker, reducing stress and helping to build their confidence. Training continues until the teacher is fully able to perform in their role of speaker/lecturer with freedom of expression. These video training sessions are the part of our media culture lessons (media culture - is a collection of ICT tools developed during the cultural and historical development in order to create public consciousness and socialization of person). After this we intend to develop a sequence of training actions to develop teachers' online facilitation skills.

Here is a description of facilitation technology which can be used in the educational process using distance learning technologies:

Step № 1. Place the students toward yourself and creation of educational motivation. Teacher greets the students with a smile. Possible forms of appeal: "Good day! (Good morning!) I greet you and invite you to overcome the several barriers on the way to achieve new top of acquiring amazing science (the name of the course). I remembered you with the warmth because I imagined your beautiful faces, smiles, curious eyes. I am sure that our time devoted to the search of scientific truth will be useful not only for you, but for me too. The pedagogue starts to work according to his curricula, permanently involving the students in partnership, in active work, using interactive methods which he has. These are the following methods: brainstorm, case-method, problem studying, heuristic methods, dialogue, different role and action games, development of joint projects, etc. Pedagogue-facilitator should possess high sensitiveness, should be able to recognize the meaning of facial expressions and gestures, feel inner state of students. Pedagogue should be able to scan the inner state of students and find the way of help and to solve problems in time. One of the reasons which cause the difficulties during on-line training is the difference in temperament of teachers and students. Sometimes a teacher-choleric teaches very rapidly, requires the same fast response from students, and speaks rapidly during expression of his thoughts, interrupts, wedging in the process of expression thoughts, thereby confusing the students. The same situation is observed from student's side. Another extreme point is on-line communication of teacher-phlegmatic, also-melancholic. Colorless and boring speech of such teacher discourages student's desire to study, distract even when there is external exertion of teacher attentiveness. Such teacher should use more illustrative material, Power Point Presentations; vary the lessons with more active involvement of students. In this way the teacher can permanently observe the students, their facial expressions, and their mood. Real pedagogue-facilitator, who is working at the level of improvisation, is able to correct the student's mood, support positive spirit of the whole group, whereby providing psychological comfort of the whole group and separate students. In the end of the lessons, teacher- facilitator summarizes the training material and offers students to visualize it. Teacher find the possibility to emphasize the participation of each student, also express his expectations from the students who were not involved in the interactive lesson. Completion of lesson is a responsible process, because the beginning and the end of the lesson is more remembered according to the laws of social psychology. The lesson finishes with the visualization of training material, repeat of general, most important elements of studied training material. Also the important element of the final stage of the lesson is self-assessment of students. Students share their feelings about their own activity or conversely passivity at the lesson; offer their suggestions about the ways how to improve the lessons and their possibilities to bring definite improvements to enhance the work of students and teachers.

Using the tools of facilitation requires the teacher to possess definite features and to have them in everyday pedagogical process. We can argue that the teacher, who recognized the importance of facilitation technology acquirement, should carry out some kind of audit of his knowledge and skill in this area. Teacher gets missing knowledge from different scientific sources, Internet and refresher courses.

One of the difficult problems is self-development of pedagogue's sensitiveness. His problem can't be solved only 
by studying on the courses. There are two ways of solving this problem: first way-participation in special trainings; second way-introspection. Introspection (lat. "introspecto", look inside)-method which allows to imagine your essence, structure, organization. This is the method of observation of your own mental processes without use of any tools and standards. The main point is that teachers have become reflective subjects. Reflection mechanism includes mental set of questions and mental answers to the questions: what does happen with my students at this time? Do we understand each other? Do I build relationships with the students in a right way? What do I need to change in my actions right now? How can I stimulate and motivate my students? What do I need to change in my communication with every student? Practice shows that less than half of teachers possess this feature. Usually, these are the teachers with deep knowledge in the area of human personality, pedagogical anthropology and pedagogical psychology, oriented at the students. The formation of facilitator features requires the lessons in training groups, where the tolerance and orientation to the interests and students personality forms with the suggestopedia methods. The main point is that the facilitation must bring the satisfaction to teachers, to enrich them by new positive emotions, in the end, to provide them professional competence growth and personal self-development.

\section{Quality Assurance in Distance Learning Education}

In modern educational community there is a point of view that distance education is presented as a universal system that allows citizens to put education on the stream. Due to this approach it is enough to have a software product (an educational portal), teachers, teaching materials (the "three pillars"), and then the system "will work». However, we believe that these "three pillars", which provide the basic scientific-methodological and material base are insufficient. We should take into account a number of other factors and organizational and pedagogical conditions when we create a unique model to an educational institution.

We suppose that there are three main conditions which create the basis of distance learning quality: quality of educational resources (learning content); quality of teachers (their professional competency); material-technical basis of educational environment. There are other problems which should be solved such as unwillingness of students for self-study; lack of motivation of the teaching staff for individualized learning system; unavailability of teaching staff to work in a virtual learning environment, a commitment to the well-established traditional system of education. The imperfection of the legal framework of distance learning should be also mentioned. There is a need to fit into the existing legal framework, which does not allow the full implementation of all types of distance learning.

The relevance of problem of quality in the distance learning system is of high demand in the context of implementing distance learning technologies in Russian educational system. The quality of education is becoming more important because of the specifics of this field of education (short period of training, mostly adult contingent of students, the need for compliance with the requirements of the market of educational services, etc.).

Problems of management and marketing, technical, technological, educational and methodological support are the main components of quality of distance learning (Figure 1). 


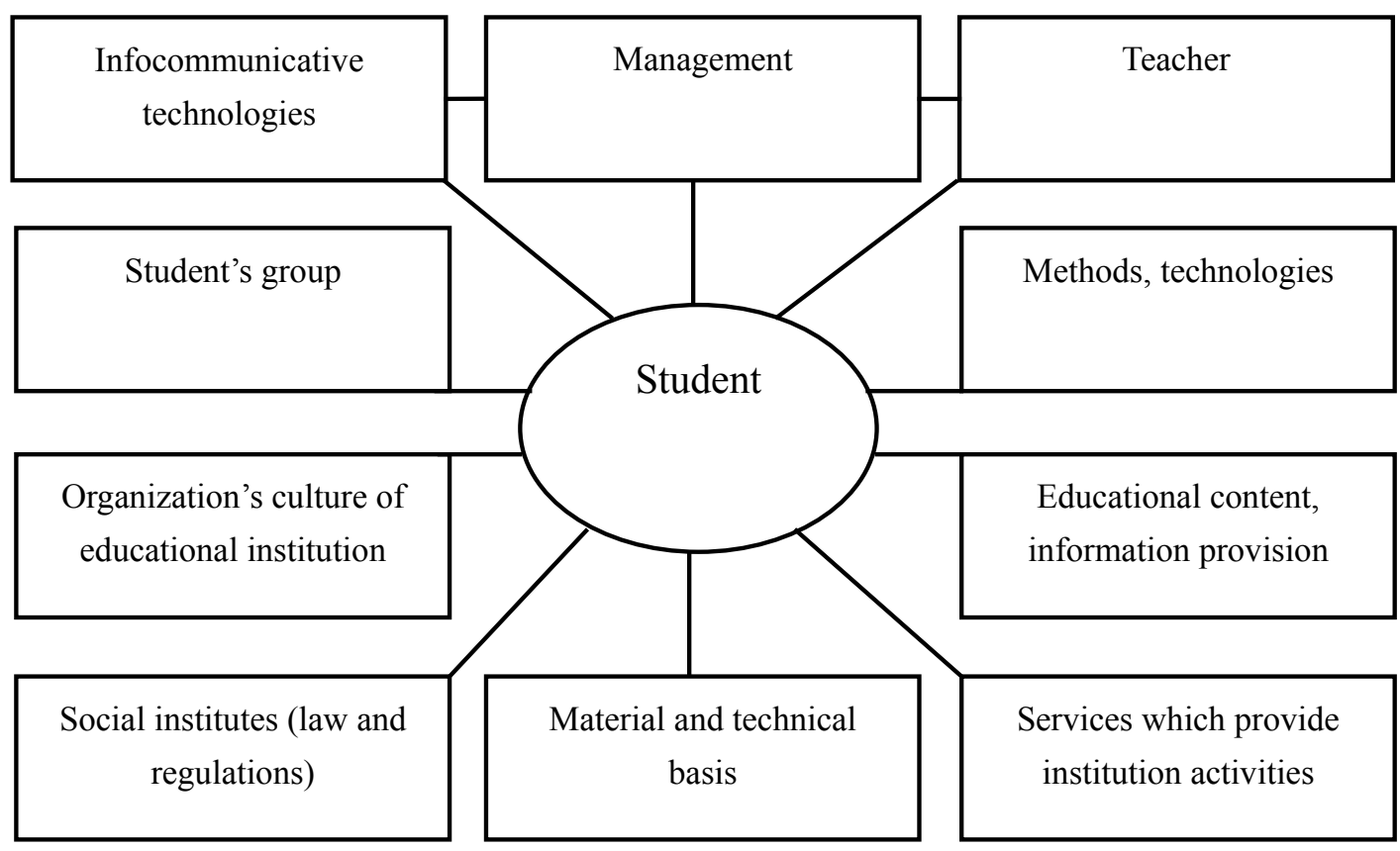

Figure 1. Educational environment of distance learning

\section{-Student}

A key figure in the educational process is a student. Quality of students' knowledge depends on its ability to learn (skills, the zone of proximal and actual development, the presence or absence of abilities to perform independent work, communication skills, the ability to systematize the educational material, level of motivation, speed of thinking, diligence, etc.). Twice a year we carry out a survey among students in order to reveal the level of their satisfaction by the educational process, also to reveal the difficulties they have in education. All students participate in this process. As usual, up to $85 \%$ of students (total amount of students - 2700) answer the questions in the survey. In addition to a survey the students have the opportunity to address their problems and questions to the administrator of e-learning portal MOODLE on technical support, system failures. During the process of improving the portal MOODLE the students suggest to improve interface or portal structure.

Methods of diagnosis: questionnaires, intelligence tests, interviews, observation, sociometry.

-Teacher

Second key figure in the educational environment of distance learning is a teacher. The teacher also develops the content (educational resources), he/she is also a tutor (consultant). Systematic meetings - seminars with teachers, where the quality of educational resources, students problems and appeals are discussed, promote correction of the mistakes and increasing the student's motivation and level of teacher's competency in the field of information technologies and e-pedagogy. The role of communicative skills of the teacher in the system if distance learning is very high. These skills include the abilities of rapid transmission of information online on the basis of a student-centered approach. Rapid response to changes in student's mood, their learning skills, increase or decrease in learning motivation of students are the most important aspects of teacher's professional competency. Computer skills, ability to work with a large massive of information, skills in psychological support are diagnosed in the system of open and distance learning (ODL).

Methods of diagnosis of proficiency, including the identification of professional skills: organizational, communicative, skills in designing and engineering, observation, expert evaluation, self-observation, questionnaires, rating of teachers, self-assessment of students, conversations.

-Technological component (methods, educational technologies, pedagogical tools and techniques)

This component requires special attention because the process of e-learning and teaching is specific: first, the educational process is interactive and secondly, it is organized on the basis of a individualization of study, thirdly, the big role is given to the independent work of students. Distance learning should be considered from the perspective of innovation, requiring innovative approaches as to the organization of the educational process, and 
to the training of teachers, who are required to possess innovative technologies, methods and means of teaching which provide an interactive educational process and stimulate the independence of students (Akhmetova, 2007).

-Informational component (educational content, information providing)

Tremendous role in the effectiveness of distance learning belongs to information provision of educational process. The student's activity depends on the quality of educational material which is located on the server, or in a case (CD) or on any media (TV and video facilities). Distance learning facilitates the use of the massive of information in the educational process, which is being improved and updated permanently. It is very important because in many areas of knowledge by the time the student finishes high school the education material becomes out of date.

Methods of expertising this component: a content-analysis of information resources, the survey of students in order to reveal the effectiveness of educational technologies, testing student's knowledge.

- Social (institutional) component

The institutional component is usually not considered by researchers of distance learning system. However, this aspect of distance learning requires special researches because the popularity of distance learning depends not only on the existing system of values and priorities, but also on the commitment of the population to the different social traditions and systems of learning that may have formed in a particular educational institution, or even the region.

- Material and technical component

Student's success and professionalism of graduates depends on the material - technical basis which ensures the educational process. Technical equipment as an essential condition to ensure the quality of distance education should be in the focus in preparation for the implementation of educational programs by distant form. Best practices of distance learning in foreign countries and in Russia show that the quality of students' knowledge depends on the quality of distance learning technologies, information communication channels.

-Organizational culture and the service of support of the educational process is reflected in the organizational culture of educational institution

There is a need to provide the general scientific-methodic culture of teachers, their willingness to "plunge" into the innovation environment. The most difficult is to assure the openness of teachers, their accessibility by special communicative channels: e-mail, phone, Skype, etc.

-Managerial component

Distance learning is a system which is managed. This statement is very important, because the organization of distance learning requires a detailed analysis of the development and station of all the factors of the educational environment. Quality management in this area is the basic key to the quality of the entire system, so the selection, training personnel, their continuing education and self-education are the basic conditions to ensure successful implementation of distance learning - from idea to realization!

Quality of educational resources is a third key component of quality. Teachers are the developers of electronic textbooks for students who do not want to be trained by e-learning portal. Using the electronic textbooks is convenient in cases where students do not have access to the Internet, do not like the Internet and use e-textbooks in electronic format (CD) or in print. Teachers receive regular consultations in the methodical center of the Institute of Distance Learning (Institute of Economics, Management and Law, Kazan, Russia) and at the Technical Assistance Center of the Institute.

One of the modern learning management system (LMS) is Moodle, which was adapted by the group of specialist of the Institute of Distance Learning (Akhmetova, Vorontsova, \& Morozova, 2013). One of the advantages of MOODLE is the opportunity to use it freely. Another important advantage of it is that it is open-source (license GNU GPL), which allows to adapt the system to the specifics of the tasks of the university, which should be solved by the system. MOODLE system offers a set of interactive elements to fill the content of the course: lectures, resources, surveys, assignments, tests, glossaries, forums, chat, video conferencing, etc. MOODLE automatically provides information on the activities of students and teachers (Akhmetova, 2009).

Organizational culture of the educational process plays an important role in quality assurance of knowledge and learning process. Our practice shows that the culture of educational process assurance consists of many indicators: organization of schedule, recording of student's success, variety of effective interactive technologies, material and technical basis of classes. The system of educational institution management IDIS allows to make the educational process more transparent and available for all - teachers, students, also it allows to unify the 
system of recording the level of knowledge of students who studies by full-time, part-time and by distant form.

In order to improve the quality of distance learning we study the experience of European organizations in the quality assurance in e-learning. European Foundation for Quality Assurance in E-learning EFQUEL is an independent accreditation agency which was founded in 2005. It has more than 120 institutional members from all over Europe and beyond-the members represent all educational sectors, schools, higher education institutions and vocational education and training organizations. In 2011 Institute of Economics, Management and Law (Kazan, Russia) became a member of EFQUEL.

EFQUEL uses the following criteria in order to evaluate the quality of e-learning in the educational institutions: strategy and e-learning, commitment to innovation, resources for e-learning, students support, technology and equipment, learning processes, assessment of Learning, Human Resources Development (Note 1). Monitoring of e-learning quality allows us to permanently track the development of the whole system and of each student.

\section{Distance learning Facilities for Inclusive Education}

Inclusive education involves the joint training of people with different educational needs and opportunities. This means that the educational process is organized by the interaction of all participants in the educational process and those who are classified as "without any disabilities", and those who have "special educational needs." Is it possible to organize distance learning interaction between students and teachers due to the implementation of inclusive approach.

Distance learning involves independent study of the student (child), using the help of a teacher (tutor). An inclusive approach is considered to involve all students in co-curricular activities. One of the main objectives of inclusive education - the development of social skills: communication, labor, and the development of tolerance and peace. To implement this task is not enough to "communicate" with a computer and a teacher, you need the group interaction. Consequently, the teacher needs to involve people with disabilities (HIA) in group training and social activities.

Despite the fact that distance learning almost doesn't allow to realize inclusive approach there are some opportunities to organize group work in the educational process. However, in our opinion, there is a certain possibility of organizing a small group interaction in the learning process. Such capabilities are realized through a variety of technologies and tools of distance learning. Let's look at some of them:

1) "Chat" is designed to organize discussions and business games in real time. There are such services as "Messaging", "Comment" which are intended for individual communication between the teacher and the student: reviewing students homework, discussing individual learning problems. Users are able to exchange text messages. Teachers direct group interaction by his/her questions in chat.

2) "Forum" is used to organize the discussion, when students can be grouped by topic. Each participant of Forum can add to his/her comment on the topic of discussion after creating it.

3) Tool "Electronic videoconferencing"-asynchronous communication environment, which can be used for the cooperation between students and teachers. This tool is a structured forum where it is possible to write an opinion, ask a question and read the answers of other participants. Electronic conferences can be organized within the local network of schools for seminars, discussions, etc. Asynchronous mode promotes reflection and, accordingly, reasonableness of questions and answers, and the possibility of using any type of files (graphics, sound, animation) which make such virtual seminars more effective.

4) Tool "videoconferencing" is synchronous, the participants interact in real time. Here one-on-one chat (consultation), one-to-many (lecture), many-to-many (teleconference) are available. This communication technology is currently used primarily in higher educational institutions, with an extensive network of branches. The main barrier for widespread use is expensive equipment, which is not always available in local training centers (branches) of the head of the institution.

5) Creating group projects by the participants of the educational process. Development of projects with the use of the virtual space can reach a large number of students. During the development of project the teacher organizes discussions in online mode, taking into account the opinion of each student. Teachers and more active students can act as the moderators. This method is effective in inclusive groups of students in order to develop leadership and communication skills.

Let's define the following means ICT in teaching people with disabilities:

- standart technologies such as computers which have special built-in functions; 
- accessible data formats known as alternative formats: for example, Digital Accessibility Information System, also law-technology formats, such as Braille system;

- assistive technologies: hearing aids, keyboard with special features,

Thus, ICT is a didactic tool which stimulates new strategy of learning and helps people with disabilities to overcome the barriers in getting new knowledge and communication.

\section{Conclusion}

Education with the use of distance learning technologies is also applicable for those who are unable to attend educational institutions (military, persons in prisons, women with young children, etc.). However, distance learning cannot be considered as the main form of inclusive education. It is possible to organize the inclusive approach in distance learning taking into account special needs of students and their differences in age, race, religion, sex, ethnicity, etc. Special attention should be paid to the socialization of students in the process of interaction between "exceptional" students with disabilities and other students.

In order to achieve this task the managers and teachers of educational institutions should possess professional skills, knowledge of psychological and physiological characteristics of the students, facilitation skills. Also they should possess the technology of organizing group work in virtual space. It is very important for students to be "heard" by their peer and by the teachers. It increases the self-esteem of "exceptional" students (Akhmetova, 2014).

The problem «inclusive approach in the educational system with the use of distance learning technologies» requires more researches because it is becoming nowadays more relevant in our society.

\section{References}

Akhmetova, D. Z. (2007). Paradoxes of distance learning. Higher Education, 3, 57-63.

Akhmetova, D. Z. (2008). Everything started with an idea. Pedagogical Education and Science, 4, 34-38.

Akhmetova, D. Z. (2009). Distance learning: From idea to realization (p. 175). Kazan: Poznaniye, Institute of Economics, Management and Law.

Akhmetova, D. Z. (2014). Incusive approach to the psycho-pedagogical assistance of learning using distance learning technologies (p. 64). Kazan: Poznaniye, Institute of Economics, Management and Law.

Akhmetova, D., Vorontsova, L., \& Morozova, I. (2013). The experience of a Distance Learning Organization in a Higher Private Educational Institution in the Republic of Tatarstan (Russia): From idea to realization. The International Review of Research in Open and Distance Learning, 14(3), 508-518. Retrieved from http://www.irrodl.org/index.php/irrodl/article/view/1428

Bernard, R. M., Abrami, P. C., Borokhovski, E., Wade, A., Tamim, R., \& Surkes, M. A (2009). A meta-analysis of three interaction treatments in distance education. Review of Educational Research, 79(3), 1243-1289.

Brushlinskiy, A. (2003). Psychology of subject (p. 272). S. Petesburg, Aleteya.

Carril, P., Sanmamed, M., \& Selles, N. (2013). Pedagogical roles and competences of University Teachers Practicing in the E-Learning Environment. The International Review of Research in Open and Distance Learning; 14(3), 1462-1487. Retrieved from http://www.irrodl.org/index.php/irrodl/article/view/1477/2613

Cleveland-Innes, M., \& Campbell, P. (2012). Emotional Presence, Learning, and the Online Learning Environment. The International Review of Research in Open and Distance Learning, 13(4), 269-292. Retrieved from http://www.irrodl.org/index.php/irrodl/article/view/1234/2347

Daniel, J., \& Marquis, C. (1979). Interaction and independence: Getting the mixture right. Teaching at a Distance, 15, 25-44.

Jung, I., \& Hong, S. (2014). An elaborated model of Student Support to Allow for Gender Considerations in Asian Distance Education. The International Review of Research in Open and Distance Learning, 15(2), 170-188. Retrieved from http://www.irrodl.org/index.php/irrodl/article/view/1604/2888

Makoe, M. (2012). Bridging the Distance: The Pedagogy of Mobile Learning in Supporting Distance Learners.

Polat, E., Bukharkina, M., \& Moiseeva, M. (2004). Theory and practice of distance learning (p. 416). Academy.

Uzuner, S. (2009). Questions of Culture in Distance Learning. The International Review of Research in Open and Distance Learning, 10(3), 1-19. $\quad$ Retrieved from http://www.irrodl.org/index.php/irrodl/article/view/690/1305 


\section{Note}

Note 1. European Foundation for Quaility in E-Learning (http://cdn.efquel.org/wp-content/blogs.dir/5/files/2012/ 09/UNIQUe_guidelines_2011.pdf)

\section{Copyrights}

Copyright for this article is retained by the author(s), with first publication rights granted to the journal.

This is an open-access article distributed under the terms and conditions of the Creative Commons Attribution license (http://creativecommons.org/licenses/by/3.0/). 